\title{
Developmental Alveologenesis: New Roles for ApoE and LDL Receptor
}

\author{
DONALD MASSARO AND GLORIA DECARLO MASSARO
}

\author{
Departments of Medicine [D.M.] and Pediatrics [G.D.M.], Georgetown University School of Medicine, Washington, District of Columbia 20057
}

\begin{abstract}
Pulmonary developmental alveologenesis occurs, in substantial part, by subdivision (septation) of the gas-exchange saccules of the morphologically immature lung. It determines the starting point of age- and disease-related alveolar loss. Because alveologenesis requires additional cell membranes, we previously asked whether apoE, which delivers lipids to cells, affects pulmonary alveologenesis; male apoE $\mathrm{E}^{-1-}$ mice had impaired alveologenesis. We now report that, in contrast to male $a p o \mathrm{E}^{-1-}$ mice, female $\mathrm{apoE}^{-1-}$ mice had full developmental alveologenesis. Among mice null for LDL receptor $\left(\mathrm{Ldlr}^{-/-}\right)$, the receptor for apoE, females had full alveologenesis; by contrast, $\mathrm{Ldll}^{-1-}$ males, as previously shown for apoE $\mathrm{E}^{-1-}$ males, had impaired alveologenesis. Thus, the absence of apoE and its receptor, Ldlr, results in impaired developmental alveologenesis in males, but their absence does not impair architectural developmental alveologenesis in females. We conclude 1) regulation of alveologenesis is a new function for apoE and Ldlr, 2) one expressed in a sexually dimorphic manner, and 3) females have different molecular requirements for alveologenesis than males, which protects them from its impairment by the absence of apoE and its receptor. (Pediatr Res 70: 458-461, 2011)
\end{abstract}

$F_{\mathrm{p} u}^{\mathrm{o}}$ ormation of the lungs' gas-exchange units (alveoli) occurs partly by subdivision (septation) of the large gas exchange saccules that constitute the gas-exchange region of the architecturally immature lung (1). Septation results in an increase of gas exchange surface area, without an equal increase of lung volume; this allows lung volume and chest size to be proportionate to body size among organisms with vastly different body mass specific rates of oxygen consumption (2). The number of pulmonary gas-exchange structures (alveoli) (3) and pulmonary gas-exchange diffusing capacity (4) vary widely among individuals in the general population who have approximately the same lung volume and are without known lung disease. This indicates the magnitude of developmental alveologenesis, nonpulmonary disease related loss of alveoli, or both differs among individuals in the general population. The basis of this variation is not understood, but the variation, all else being equal, will affect the onset of symptoms and disability, with the progression of diseases that destroy alveoli, e.g. chronic obstructive pulmonary disease and pulmonary fibrosis. Thus, information on genetic determinants of full developmental alveologenesis is essential for the eventual

Received March 22, 2011; accepted May 26, 2011.

Correspondence: Donald Massaro, M.D., Lung Regeneration Laboratory, Georgetown University School of Medicine, Preclinical Science Building, GM-12, 3900 Reservoir Road NW, Washington, DC 20057; e-mail: massarod@georgetown.edu

Supported by NHLBI grant 020366-35.

The authors report no conflicts of interest. understanding of the wide variation of the number of alveoli among humans with similar lung volumes. Because alveologenesis requires additional cell membranes, we previously asked whether apoE, which delivers lipids to cells, affects pulmonary alveologenesis. We found $\mathrm{apoE}^{-/-}$male mice have impaired alveologenesis (5). Because the regulation of developmental alveologenesis differs between sexes (6) and to determine whether LDL receptor (Ldlr), the receptor for apoE, was involved in the effect the absence of apoE had on developmental alveologenesis, we now tested the effect on developmental alveologenesis, of the absence of apoE in female mice, and of the absence of Ldlr, in male and female mice.

\section{METHODS}

Animal care and anesthesia. We purchased male and female C57BL/6J (WT) mice, female apoE null (B6.129P2-Apoe ${ }^{t m 1 U n c}$ ) mice, and LDL receptor null (B6.129S7-Ldlr ${ }^{\mathrm{tm} 1 \mathrm{Her} / \mathrm{J}}$ ) mice from Jackson Laboratory (Bar Harbor, ME). Upon arrival at Georgetown University, all mice were housed in the Department of Comparative Medicine, maintained on a 12:12-h light-dark cycle, and allowed Rodent Chow 5001 (LabDiet; Quality Lab Products, Elkridge, MD) and tap water ad libitum. Mice were killed by cutting great vessels in the abdomen after achieving a surgical level of anesthesia, indicated by failure to withdraw from a toe pinch, by injecting xylazine (Akom, Inc, Decatur, IL; $\sim 10 \mathrm{mg} / \mathrm{kg}$ ) plus ketamine (Fort Dodge Animal Health, Fort Dodge, IA; $\sim 75 \mathrm{mg} / \mathrm{kg}$ ) s.c. through a 27 -gauge needle. All procedures were approved by the Georgetown University Animal Care and Use Committee and comply with the National Institutes of Health Guidelines.

Lung fixation for morphometry. Cold $2.5 \%$ glutaraldehyde (Electron Microscopy Sciences, Hatfield, PA) in $0.1 \mathrm{M}$ sodium cacodylate buffer (Electron Microscopy Sciences), $\mathrm{pH}$ 7.4, was infused into the trachea at a constant transpulmonary pressure of $20 \mathrm{~cm} \mathrm{H}_{2} \mathrm{O}$ after the diaphragm had been pierced from its abdominal surface. Trachea were ligated, lungs removed from the thorax, and fixation continued for $2 \mathrm{~h}$ at $0-4^{\circ} \mathrm{C}$. Lung volume was measure by volume displacement (7). Lungs were cut into blocks; blocks were selected for study using a systematic sampling technique $(8,9)$. The selected blocks were rinsed in cacodylate buffer, postfixed in buffered osmium tetroxide (Electron Microscopy Sciences), dehydrated, and embedded in epoxy resin (Poly/Bed 812; Polysciencs Inc., Warrington, PA).

Morphometric procedures. Serial sections of lung were cut at about 0.8 $\mu \mathrm{m}$ for analysis by light microscopy. We sectioned three to five blocks per animal, and each group of serial sections is cut to a depth of $250-300 \mu \mathrm{m}$. To distinguish alveolar airspace from alveolar duct airspace, gas-exchange structures were followed through a complete set of prints of serially sectioned lung. All analyses were done on coded prints made from sections mounted on glass slides, stained with toluidine blue, and photographed with a Reichert Microstar IV microscope on Polaroid 667 film (Electron Microscopy Sciences). The selector method was used to choose alveoli for analysis, and the disector and point-sampled intercepts method (10) were used to estimate the volume of individual alveoli; these methods allow structures to be selected based on number rather than size, shape, or orientation. We analyzed 30-50 alveoli per mouse. The volume of an alveolus was calculated from serial measurements

Abbreviations: Ldlr, LDL receptor; $L_{\mathbf{m}}$, distance between alveolar walls; $N_{\mathrm{a}}$, number of alveoli; $S_{\mathrm{a}}$, surface area; $S / V$, surface to volume ratio; $V_{\mathrm{a}}$, volume of an average alveolus; $\boldsymbol{V}_{\mathbf{v}}$, volume density or volume fraction 
of the same alveolus using the expression $v_{\text {est }}=\pi / 3 \times l_{\theta}^{-3}$, where $v_{\text {est }}$ is the individual estimated volume and $l_{0}^{-3}$ is the average cubed segment. Mean alveolar volume $\left(V_{\mathrm{a}}\right)$ was obtained from the arithmetic mean of the individual estimates. We determined alveolar surface area, mean linear intercept $\left(L_{\mathrm{m}}\right.$, distance between alveolar walls), $S / V$ (alveolar surface-to-volume ratio), and the $V_{\mathrm{v}}$ (volume density i.e., volume fraction) of alveolar walls and gasexchange air space (alveolar and alveolar duct air space) by point and intercept counting $(11,12) ; L_{\mathrm{m}}$ and alveolar surface-to-volume ratio are estimates of the size of gas-exchange units.

Statistical analysis. For each parameter measured, or calculated from measurements, the values for individual animals were averaged per experimental group, and the SD of the group mean was calculated. The statistical significance of the difference between two groups was obtained by an unpaired two-tailed $t$ test (StatMost 32; Dataxiom Software, Inc. Los Angeles, CA).

\section{RESULTS}

Body mass, nose-rump length, and gas-exchange region dimensions of WT compared with apo $E^{-/-}$3-mo-old female mice. We did not find differences between 3-mo-old female WT and apoE $\mathrm{E}^{-/-}$mice of body mass, nose-rump length, lung volume, and volume density (volume fraction, $V_{v}$ ) of gasexchange region air or tissue, or volume of gas-exchange region air or tissue (Table 1 ). Thus, in 3-mo-old WT and apoE $^{-/-}$female mice, genotype did not detectably affect the relative $\left(V_{\mathrm{v}}\right)$, or absolute, volume of components of the gasexchange structures. Furthermore, $L_{\mathrm{m}}$, which denotes the distance between alveolar walls, a distance that can comprise alveolar duct air space plus alveolar air space, did not differ between genotypes; nor did the ratio of gas-exchange region surface area to gas-exchange region volume, i.e. the surfaceto-volume ratio. Among measurements that exclude alveolar ducts, we did not find differences of the volume of an average alveolus $\left(V_{\mathrm{a}}\right)$, number of alveoli $\left(N_{\mathrm{a}}\right)$, alveolar surface area $\left(S_{\mathrm{a}}\right)$, or body mass specific alveolar surface area between WT and apoE $\mathrm{E}^{-/-}$female mice (Table 1). These measurements of alveolar dimensions, which exhibit complete internal consistency, indicate that the absence of apoE in female mice did not result in impaired architectural developmental alveologenesis. Thus, unlike apoE $\mathrm{E}^{-/-}$male mice, which have impaired architectural developmental alveologenesis (5), apoE $\mathrm{E}^{-/-}$female mice do not have impaired developmental alveologenesis.

Table 1. Alveolar dimensions in 3-mo-old WT and apoE ${ }^{-/-}$ female mice

\begin{tabular}{lccc}
\hline \multicolumn{1}{c}{ Parameter } & \multicolumn{1}{c}{ C57BL/6J } & ApoE & \\
& $(3)$ & $-/-(3)$ & $p$ \\
\hline Body mass, g & $20.1 \pm 1.2$ & $19.8 \pm 0.7$ & 0.8 \\
Nose-rump, mm & $85.0 \pm 1.4$ & $83.7 \pm 1.2$ & 0.4 \\
Lung volume, mL & $0.70 \pm 0.05$ & $0.67 \pm 0.0$ & 0.6 \\
$V_{\mathrm{v}}$ gas-exchange air & $0.79 \pm 0.02$ & $0.78 \pm 0.02$ & 0.8 \\
$V_{\mathrm{v}}$ gas-exchange tissue & $0.17 \pm 0.01$ & $0.17 \pm 0.02$ & 0.8 \\
Gas-exchange air, mL & $0.55 \pm 0.06$ & $0.54 \pm 0.05$ & 0.7 \\
Gas-exchange tissue, $\mathrm{mL}$ & $0.12 \pm 0.01$ & $0.11 \pm 0.02$ & 0.7 \\
$L_{\mathrm{m}}, \mu \mathrm{m}$ & $78.2 \pm 4.8$ & $75.0 \pm 3.8$ & 0.5 \\
$S / V, \mathrm{~cm}^{-1}$ & $555 \pm 36.0$ & $532 \pm 27.0$ & 0.5 \\
$V_{\mathrm{a}}, \mu \mathrm{m}^{3} \times 10^{-4}$ & $4.1 \pm 0.2$ & $4.4 \pm 0.5$ & 0.5 \\
$N_{\mathrm{a}} \times 10^{-6}$ & $8.96 \pm 0.08$ & $8.42 \pm 1.3$ & 0.6 \\
$N_{\mathrm{a}} /{\mathrm{kg} \times 10^{-6}}_{S_{\mathrm{a}}, \mathrm{cm}^{2}}^{444 \pm 22.4}$ & $426 \pm 65.6$ & 0.7 \\
\hline
\end{tabular}

Means \pm SDs are given. Figures in parentheses indicate the number of mice.

$N_{\mathrm{a}} / \mathrm{kg}$, number of alveoli per body mass.
Body mass, nose-rump length, lung volume, and dimensions of the gas-exchange region of 5-mo-old WT and $\mathbf{L d l r}^{-/-}$male mice. Body mass, but not nose-rump length or lung volume, was lower at age 5 mo in $\mathrm{Ldlr}^{-1-}$ than in WT male mice (Table 2). Volume density $\left(V_{\mathrm{v}}\right)$ of gas-exchange air was higher, and volume density of gas-exchange tissue was lower in $\mathrm{Ldlr}^{-1-}$ than in WT males. The difference of the means of gas-exchange air volume between WT and $\mathrm{Ldlr}^{-1-}$ males did not achieve a statistical significance, but the volume of gas-exchange tissue was lower in $\mathrm{Ldlr}^{-1-}$ than in WT male mice. This difference of gas-exchange tissue volume would be expected if, as found, vide infra, the large gas-exchange saccules present at birth were not subdivided (septated) as much in $\mathrm{Ldlr}^{-/-}$as in WT male mice, resulting in less gas-exchange tissue in the mutants than in the WT mice.

The distance between alveolar walls $\left(L_{\mathrm{m}}\right)$ was greater, and the ratio of gas-exchange surface area to gas-exchange tissue volume $(S / V)$ was less in $\mathrm{Ldlr}^{-1-}$ than in WT males (Table 2). The differences of $L_{\mathrm{m}}$ and surface-to-volume ratio between WT and $\mathrm{Ldlr}^{-1-}$ mice indicate diminished septation of the gas-exchange saccules present at birth in $\mathrm{Ldlr}^{-1-}$ mice. To further test this possibility, we determined the average volume of alveoli and calculated the number of alveoli. The volume of an average alveolus $\left(V_{\mathrm{a}}\right)$ was greater, alveolar number $\left(N_{\mathrm{a}}\right)$ lower, and alveolar surface area $\left(S_{\mathrm{a}}\right)$ less in $\mathrm{Ldlr}^{-1-}$ than in WT male mice. These measurements of the dimensions of the gas-exchange structures are all internally consistent and indicate architectural developmental alveologenesis was less in $\mathrm{Ldlr}^{-/-}$males than in WT males. All other predispositions to disease, aging, or both being equal means $\mathrm{Ldlr}^{-/-}$male mice, as apoE $\mathrm{E}^{-1-}$ male mice (5), begin age- or disease-related alveolar loss with fewer alveoli than WT mice, and hence would be at a disadvantage, as would humans in the same situation.

Body mass, nose to rump length, lung volume, and dimensions of the gas-exchange region of 1-mo-old WT and $\mathbf{L d l r}^{-/-}$male mice. To diminish the possibility alveolar loss following initial full alveologenesis might be responsible for our morphometric findings in 5-mo-old $\mathrm{Ldlr}^{-1-}$ male mice,

Table 2. Body mass, nose-rump length, lung volume, and alveolar dimensions of 5-mo-old C57BL/6J and Ldlr ${ }^{-1-}$ male mice

\begin{tabular}{|c|c|c|c|}
\hline Parameter & C57BL/6J & $\mathrm{Ldll}^{-1-}$ & $p$ \\
\hline Body mass, $g$ & $32.0 \pm 1.6(4)$ & $29.4 \pm 0.4(4)$ & 0.03 \\
\hline Nose-to-rump, mm & $.8 \pm 0.8(4)$ & $3.3 \pm$ & 0.2 \\
\hline Lung volume, $\mathrm{mL}$ & $81 \pm 0.0(4)$ & $0.83 \pm 0.04$ & 0.5 \\
\hline$V_{\mathrm{v}}$ gas-exchange air & $79 \pm 0.0$ & $0.83 \pm 0.02(4)$ & $<0.05$ \\
\hline$V_{\mathrm{v}}$ gas-exchange tissue & $0.19 \pm 0.0$ & $0.14 \pm 0.00$ & 0.004 \\
\hline Gas-exchange air, $\mathrm{mL}$ & $64=$ & $0.68 \pm$ & 0.2 \\
\hline Gas-exchange tissu & $0.15=$ & $0.11 \pm$ & 0.004 \\
\hline$L_{\mathrm{m}}, \mu \mathrm{m}$ & $66.3 \pm 1.0(4)$ & $81.8 \pm 4.3(4)$ & 0.0004 \\
\hline$S / V, \mathrm{~cm}^{-1}$ & $607 \pm 6.9$ & $498 \pm 26.7(4)$ & 0.0001 \\
\hline$V_{\mathrm{a}}, \mu \mathrm{m}^{3} \times 10^{-4}$ & $4.5 \pm 0.6(3)$ & $7.9 \pm 0.9(3)$ & 0.01 \\
\hline$N_{\mathrm{a}} \times 10^{6}$ & $10.1 \pm 0.8(3)$ & $5.3 \pm 0.5(3)$ & 0.002 \\
\hline$N_{\mathrm{a}} / \mathrm{kg}$ body mass $\times 10^{6}$ & $306 \pm 40.5(3)$ & $180 \pm 19.3(3)$ & 0.009 \\
\hline$S_{\mathrm{a}}, \mathrm{cm}^{2}$ & $387 \pm 11.6$ & $334 \pm 40.9(4)$ & 0.05 \\
\hline$S_{\mathrm{a}} / \mathrm{g}$ body mass, $\mathrm{cm}^{2} / \mathrm{g}$ & $12.1 \pm 0.8$ & $11.4 \pm 1.1(4)$ & 0.4 \\
\hline
\end{tabular}

Mean \pm SDs are given. Figures in parentheses indicate the number of mice.

$N_{\mathrm{a}} / \mathrm{kg}$, number of alveoli per body mass; $S_{\mathrm{a}} / \mathrm{g}$, alveolar surface area per body mass. 
we assessed developmental alveologenesis in 1-mo-old WT and $\mathrm{Ldlr}^{-1-}$ male mice. One-month-old $\mathrm{Ldlr}^{-1-}$ male mice weighed less than, and were not as long as, same age WT males (Table 3). Lung volume was lower in $\mathrm{Ldlr}^{-/-}$than in WT mice, and the volume density of gas-exchange air did not differ between genotypes but that of gas-exchange tissue was lower in $\mathrm{Ldll}^{-/-}$than WT males. The volume of gas-exchange air did not achieve a statistical difference between genotypes, but the volume of alveolar walls was lower in $\mathrm{Ldlr}^{-/-}$than in WT males reflecting, at least in part, the lower lung volume in $\mathrm{Ldlr}^{-1-}$ males. The distance between alveolar walls $\left(L_{\mathrm{m}}\right)$ was higher and the surface-to-volume $(S / V)$ ratio of gas-exchange structures was lower in $\mathrm{Ldlr}^{-1-}$ than in WT males at age 1 mo. The volume of an average alveolus was greater, the number of alveoli smaller, alveolar surface area, and body mass specific alveolar surface area were lower in $\mathrm{Ldlr}^{-1-}$ compared with WT males (Table 3). These data, which demonstrate complete internal consistency, indicate impaired architectural developmental alveologenesis, rather than alveolar loss following unimpaired alveologenesis, resulted in the larger and fewer alveoli present in 5-mo-old $\mathrm{Ldlr}^{-1-}$ compared with 5-mo-old WT males. Thus, unlike $\mathrm{Ldll}^{-1-}$ female mice, the absence of Ldlr in male mice impairs architectural developmental alveologenesis, as does the absence of its ligand, apoE, in male (5) but not in female mice (Table 1).

Body mass, nose-rump length, lung volume, and dimensions of the gas-exchange region of 5-wk-old WT and $\mathrm{Ldlr}^{-/}$ -female mice. At age $5 \mathrm{wk}$, body mass and nose-rump length were less in $\mathrm{Ldlr}^{-/-}$than WT female mice, but none of the dimensions of the gas-exchange structures differed between genotypes (Table 4). Thus, in females neither Ldlr (Table 4) nor apoE (Table 1) are required for full architectural developmental alveologenesis, whereas in males, the absence of either apoE or Ldlr (Tables 2 and 3) impairs architectural developmental alveologenesis.

Table 3. Body mass, nose-rump length, lung volume, and gas-exchange region dimensions of 1-mo-old C57BL/6J and $\mathrm{Ldlr}^{-1-}$ male mice

\begin{tabular}{|c|c|c|c|}
\hline Parameter & $\mathrm{C} 57 \mathrm{BL} / 6 \mathrm{~J}$ & $\mathrm{Ldlr}^{-1-}$ & $p$ \\
\hline Body mass, $\mathrm{g}$ & $16.4 \pm 0.9(4)$ & $13.8 \pm 1.2(4)$ & 0.01 \\
\hline Nose-to-rump, mm & $78.2 \pm$ & $72.5 \pm 3.7(5)$ & $<0.05$ \\
\hline Lung volume, mL & $0.51 \pm 0.02$ & $0.42 \pm 0.05(5)$ & 0.025 \\
\hline$V_{\mathrm{v}}$ gas-exchange air & $0.78 \pm$ & $0.80 \pm 0.03(5)$ & 0.2 \\
\hline$V_{\mathrm{v}}$ gas-exchange tissue & $0.19 \pm$ & $0.17 \pm$ & 0.006 \\
\hline Gas-exchange air, $\mathrm{mL}$ & $0.39=$ & $0.34 \pm$ & 0.06 \\
\hline Gas-exchange ti & $0.09=$ & $0.08 \pm$ & $<0.009$ \\
\hline$L_{\mathrm{m}}, \mu \mathrm{m}$ & $62.0=$ & $75.0 \pm 3.7(5)$ & $<0.001$ \\
\hline$S / V, \mathrm{~cm}^{-1}$ & $643 \pm 10.7(4)$ & $534 \pm 28.8(5)$ & 0.0006 \\
\hline$V_{\mathrm{a}}, \mu \mathrm{m}^{3} \times 10^{-4}$ & $2.80 \pm 0.14(3)$ & $4.46 \pm 0.23(3)$ & $<0.002$ \\
\hline$N_{\mathrm{a}} \times 10^{6}$ & $9.57 \pm 0.27(3)$ & $4.43 \pm 0.34(3)$ & 0.000004 \\
\hline$N_{\mathrm{a}} / \mathrm{kg}$ body mass $\times 10^{6}$ & $590 \pm 6.6(3)$ & $323 \pm 5.8(3)$ & 0.0001 \\
\hline$S_{\mathrm{a}}, \mathrm{cm}^{2}$ & $252 \pm 7.5$ & $175 \pm 29.0(5)$ & 0.005 \\
\hline$S_{\mathrm{a}} / \mathrm{g}$ body mass, $\mathrm{cm}^{2} / \mathrm{g}$ & $15.4 \pm 0.9(4)$ & $13.3 \pm 1.1(5)$ & $<0.02$ \\
\hline
\end{tabular}

Means \pm SDs are given. Figures in parentheses indicate the number of mice.

$N_{\mathrm{a}} / \mathrm{kg}$, number of alveoli per body mass; $S_{\mathrm{a}} / \mathrm{g}$, alveolar surface area per body mass.
Table 4. Body mass, nose-rump length, lung volume, and gas exchange region dimensions of 5-wk-old C57BL/6J and $\mathrm{Ldlr}^{-1-}$ female mice

\begin{tabular}{llll}
\hline \multicolumn{1}{c}{ Parameter } & \multicolumn{1}{c}{$\begin{array}{c}\text { C57BL/6J } \\
(4)\end{array}$} & $\begin{array}{c}\mathrm{Ldlr}^{-/-} \\
(4)\end{array}$ & $p$ \\
\hline Body mass, g & $16.6 \pm 0.8$ & $15.0 \pm 0.7$ & 0.04 \\
Nose-to-rump, mm & $81.0 \pm 2.2$ & $76.5 \pm 1.5$ & 0.02 \\
Lung volume, mL & $0.56 \pm 0.02$ & $0.52 \pm 0.02$ & 0.12 \\
Lung volume/body mass, & $33.5 \pm 1.6$ & $34.4 \pm 0.9$ & 0.4 \\
$\quad$ mL/kg & & & \\
$V_{\mathrm{v}}$ gas-exchange air & $0.76 \pm 0.02$ & $0.77 \pm 0.03$ & 0.6 \\
$V_{\mathrm{v}}$ gas-exchange tissue & $0.21 \pm 0.02$ & $0.20 \pm 0.02$ & 0.8 \\
Gas-exchange air, mL & $0.42 \pm 0.01$ & $0.39 \pm 0.02$ & 0.09 \\
Gas-exchange tissue, mL & $0.11 \pm 0.02$ & $0.11 \pm 0.02$ & 1.0 \\
$L_{\mathrm{m}}, \mu \mathrm{m}$ & $67.8 \pm 8.2$ & $67.8 \pm 3.3$ & 1.0 \\
$S / V, \mathrm{~cm}^{-1}$ & $598 \pm 68.0$ & $592 \pm 27.4$ & 0.9 \\
$S_{\mathrm{a}}, \mathrm{cm}^{2}$ & $251 \pm 30.2$ & $232 \pm 20.4$ & 0.4 \\
$S_{\mathrm{a}} / \mathrm{g}$ body mass, $\mathrm{cm}^{2} / \mathrm{g}$ & $15.1 \pm 2.0$ & $15.5 \pm 1.2$ & 0.8 \\
\hline
\end{tabular}

Means \pm SDs are given. Figures in parentheses indicate the number of mice.

$S_{\mathrm{a}} \mathrm{g}$, alveolar surface area per body mass.

\section{DISCUSSION}

Developmental alveologenesis. In all mammalian species of which we are aware, developmental pulmonary alveologenesis includes subdivision (septation) of the saccules that constitute the gas-exchange region of the architecturally immature lung (1). This process is prenatal in precocial species such as guinea pigs and range animals; postnatal in altricial organisms, e.g. mice and rats; and late prenatal and postnatal, probably to cessation of linear growth in humans. Septation increases the gas-exchange surface area of the lung without an equal increase of lung volume, i.e. the surface-to-volume ratio of the gas exchange structures is increased by septation. Greater septation in animals with high body mass specific oxygen consumption, compared with those with low body mass specific oxygen consumption, allows the former to meet their greater relative need for oxygen without requiring a chest that is disproportionately large compared with the rest of the body (2).

In sexually virgin WT mice and rats, females have smaller alveoli and, per body mass, more numerous alveoli, and a greater alveolar surface area, without an intersex difference in body mass specific oxygen consumption (11). However, body mass specific oxygen consumption may be 2-fold higher during pregnancy and lactation (11). This is consistent with the notion differences in the extent of developmental alveologenesis between male and female mice and rats evolved to meet the energy needs of females during reproduction. The greater alveologenesis in females occurs before the actual energy requirements of reproduction take place, suggesting this difference of alveologenesis was evolutionarily selected because it did not add, to the already large energy cost to females of reproduction, the energy cost of producing more alveoli to meet the increased oxygen requirements of pregnancy and lactation (11). WT sexual dimorphism of alveolar size, body mass specific number of alveoli, and alveolar surface area is absent in estrogen receptor alpha null mice indicating it is mediated via estrogen receptor alpha (12). By 
contrast, male mice genetically deficient in androgen receptors have the same body mass specific alveolar surface area as litter mates without a deficiency of androgen receptors (13). Prior work with male apoE mice (5) and the present work demonstrate a new role for apoE and Ldlr and involvement in developmental pulmonary alveologenesis in a sexually dimorphic manner, associated with the absence of apoE or Ldlr.

In summary, 1) we identified new roles for the long, intensively, studied molecules apoE and Ldlr, i.e. roles in developmental pulmonary alveologenesis; 2) the roles are sexually dimorphic_-males require apoE and Ldlr for full developmental alveologenesis and females do not; 3) these findings indicate females use a different molecular mechanism for developmental alveologenesis than males, one that does not require apoE or Ldlr, or, in the absence of apoE and or its receptor, females have a back-up molecular mechanism for developmental alveologenesis; and 4) our findings are consistent with the greater quantitative importance of females to survival of a species than males.

Acknowledgments. We thank Helene Hadden, M.D., Ph.D., for critically reading an early version of the manuscript and for helpful suggestions and Ms. Zofia Opalka for expert technical assistance.

\section{REFERENCES}

1. Massaro GD, Massaro D 1996 Formation of pulmonary alveoli and gas-exchange surface area: quantitation and regulation. Annu Rev Physiol 58:73-92

2. Tenney SM, Remmers JE 1963 Comparative quantitative morphology of mammalian lung: diffusing area. Nature 197:54-56

3. Angus GE, Thurlbeck WE 1972 Number of alveoli in human lung. J Appl Physiol 32:483-485

4. Neas LM, Schwartz J 1996 The determinants of pulmonary diffusing capacity in a national sample of U.S. adults. Am J Respir Crit Care Med 153:656-664

5. Massaro D, Massaro GD 2008 Apoetm1Unc mice have impaired alveologenesis, low lung function, and rapid loss of lung function. Am J Physiol Lung Cell Mol Physiol 294:L991-L997

6. Massaro D, Massaro GD 2006 Estrogen receptor regulation of pulmonary alveolar dimensions: alveolar sexual dimorphism in mice. Am J Physiol Lung Cell Mol Physiol 290:L866-L870

7. Scherle W 1970 A simple method for volumetry of organs in quantitative stereology. Mikroskopie 26:57-60

8. Massaro GD, Massaro D 1996 Postnatal treatment with retinoic acid increases the number of alveoli in rats. Am J Physiol 270:L305-L310

9. Massaro GD, Massaro D 1997 Retinoic acid treatment abrogates elastase-induced pulmonary emphysema in rats. Nat Med 3:675-677

10. Cruz-Orive LM 1987 Particle number can be estimated using a disector of unknown thickness: the selector. J Microsc 145:121-142

11. Massaro GD, Mortola JP, Massaro D 1995 Sexual dimorphism in the architecture of the lung's gas-exchange region. Proc Natl Acad Sci USA 92:1105-1107

12. Massaro D, Clerch LB, Massaro GD 2007 Estrogen receptor-alpha regulates pulmonary alveolar loss and regeneration in female mice: morphometric and gene expression studies. Am J Physiol Lung Cell Mol Physiol 293:L222-L228

13. Massaro GD, Mortola JP, Massaro D 1996 Estrogen modulates the dimensions of the lung's gas-exchange surface area and alveoli in female rats. Am J Physiol 270:L110-L114 